\title{
Device Unattended
}

National Cancer Institute

\section{Source}

National Cancer Institute. Device Unattended. NCI Thesaurus. Code C53274.

A situation when a procedure or operation involving use of medical device is performed without required level of care, supervision, or constant observation by a person who is qualified and knowledgeable regarding the device operation and safety procedures. 